\title{
Editorial
}

\section{O álcool na Clínica Médica}

U ma das funções mais importantes da medicina moderna é alertar a popul ação como um todo e os pacientes em particular sobre al guns comportamentos e suas implicações sobre a saúde. As três principais causas de mortalidade que poderiam ser evitadas nos EUA, correspondendo a cerca de $40 \%$ dessas mortes, dizem respeito ao fumo, dieta e consumo de álcool . Dados americanos também mostram que uma em cada dez mortes naquele país tem o álcool como o fator mais importante. Também em relação as despesas médicas as doenças associadas ao álcool representam $20 \%$ dos cursos hospitalares nos EUA. Somente com a perda relacionada ao trabal ho o ál cool representam um custo de U\$ 70 bilhões ao ano.

Rosa et al. apresentam na página 335 dados importantes sobre o abuso do ál cool em pacientes do Hospital de Clínicas de Porto Alegre, e sua identificação pelos profissionais de saúde. Mostraram que somente $51 \%$ dos pacientes que foram identificados por um screening (CAGE ) foram ao mesmo tempo identificados pela equipe médica. Esses dados já haviam sidos mostrados na literatura internacional por Cleary et al.(1988) e Buchsbaum et al. (1992) que também enfatizaram que aparentemente existem algumas barreiras em relação aos pacientes com beber problemático. Pode-se citar: 1 - a falta de treinamento dos médicos em relação ao álcool; 2- falta de confiança na habilidade de aconsel hamento desses pacientes; 3 - ceti cismo terapêutico devido a experiências anteriores com pacientes parecidos; 4 - preocupação com a falta de tempo; 5 - alocação de prioridades para outros tipos de pacientes.

Vários estudos têm demonstrado que pacientes com beber problemático respondem à intervenções breves feitas por médicos e outros profissionais de saúde (Institute of Medicine, 1990). Mostrou-se que educação sobre os efeitos doál cool, aconsel hamentos bási co de como ficar abstinentes ou diminuir o consumo, monitoramento das complicações médi cas relacionadas ao consumo de álcool, e acompanhamento ambulatorial feito pel o clínico, são efetivos em reduzir a morbidade relacionada ao álcool. Um fator de extrema importância é o treinamento dos médicos. Em um estudo recente Ockene et al. (1997) avaliaram o impacto de um treinamento breve em profissionais trabal hando em cuidados primários de saúde. O treinamento consistia de duas horas de aulas em grupo e um ou dois períodos de 30 minutos de treinamentos individuais em rel ação ao aconsel hamento estruturado para pacientes com probl emas com ál cool. Esta intervenção simples com esses profissionais foi capaz de alterar a capacidade de aconseIhamento, atitudes e conhecimentos dos problemas relacionados com o álcool.

Várias iniciativas internacionais vêm tentando modificar uma certa apatia que existe na clínica médica em lidar com os problemas do álcool. A própria Organização Mundial da Saúde tem tido várias iniciativas. Dentre elas, o desenvol vimento de um questionário simples de screening com 10 perguntas, chamado de AUDIT, que poderia ser usado por qualquer profissional desaúde. Além disso, a OMS busca estimular iniciativas no setor de cuidados primários de saúde que possam orientar esses pacientes. NoS EUA o National Institute of Health também tem recentemente organizado uma série de esforços visando o treinamento dos clínicos. E m uma publi cação recente $(\mathrm{NIH}$, 1995) recomenda que os clínicos poderiam ajudar os seus pacientes seguindo quatro passos: 1 - pergunte sobre o uso de ál cool ; 2 - Avalieos problemas relacionados com o abuso com o abuso de álcool ; 3 - Aconsel he diretamente a ação mais apropriada (diminuir o consumo, abstinência ou procurar um tratamento especializado); 4 - Monitorar o progresso do paciente. Na Inglaterra os clínicos gerais têm, sob contrato, a obrigação de perguntar para todos os pacientes sobre o consumo de ál cool e fumo. Visa-se um monitoramento constante dessas duas condições, pois pesquisas nesse país 
também mostraram que essas ações simples são efetivas em diminuir consumo.

No Brasil estamos muito longe de conseguir ter um tratamento adequado para esses pacientes. Eles continuam não sendo detectados no setor de cuidados primários de saúde, não são atendidos pelos poucos serviços especializados existentes, e além disso a grande maioria dos profissionais não recebeu treinamento na escola médica em como fazer um aconselhamento básico. Poderíamos esperar alguma iniciativa por parte do Ministério da Saúde no sentido de termos uma política a respeito desse problema de saúde pública que é o consumo abusivo de álcool, mas as chances disto acontecer num futuro recente são mínimas. I niciativas como essa do Hospital de Clínicas de Porto Alegre que aumenta a consciência dos profissionais sobre o problema e iniciativas de outras organizações médicas no sentido de melhorar o nível de conhecimento dos médicos sobre o álcool parece ser a saída mais realista.

\section{Ronaldo Laranjeira}

Ph. D em Psiquiatria pela Universidade de Londres; Coordenador da Unidade de Pesquisa em Álcool e DrogasEscola Paulista de Medicina-Unifesp.

1. Cleary, P. et al. Prevalence and recognition of alcohol abuse in a primary care population. Am. J . Med. 1988;85;466-71.

2. Buchsbaum, D. et al. Physical detection of drinking problems in patients attending a general medicine practice. J. Gen Intern. Med. 1992, 7:517-21.

3. Institute of Medicine. Brodening the Base of Treatment for Alcohol Problems. Washington, DC: National Academy Press; 1990.

4. Rosa, A. A. et al. Percepção e registro de abuso de ál cool e de doenças relacionadas num hospital geral universitário. Rev. Ass Med Brasil 1998; 44(4): 335-9.

5. Ockene, J.K. et al. Provider training for patiente-centered alcohol counseling in a primary care setting. Arch. Intern. Med. 1997, 157: 2.334-41.

6. National Institute of Health. The Physicians' Guide to Helping Patients with Alcohol Problems, 1995. 